\title{
Programmable reactivity-based one-pot oligosaccharide synthesis
}

\author{
Jinq-Chyi Lee, William A Greenberg \& Chi-Huey Wong
} Department of Chemistry and the Skaggs Institute for Chemical Biology, The Scripps Research Institute, 10550 North Torrey Pines Road, La Jolla, California 92037, USA.
Correspondence should be addressed to C.-H.W. (wong@scripps.edu).

Published online 31 January 2007; doi:10.1038/nprot.2006.489

\begin{abstract}
A detailed protocol is described for the application of a programmable one-pot oligosaccharide synthesis methodology to the synthesis of fucosyl GM1. This serves as a general example of the application of this method to the synthesis of any desired oligosaccharide. The method relies on a large database of relative reactivities for differentially protected tolyl thioglycoside donor molecules and a computer program to suggest the best order of addition for assembly of the oligosaccharide in optimal yield and with the fewest operations. The product is a protected form of the desired oligosaccharide isolated in $47 \%$ yield, which is then deprotected using standard procedures to provide fucosyl GM1 oligosaccharide (1) in $44 \%$ yield. The total time for synthesis of 1 from building blocks 3,4 and 5 is approximately $4 \mathrm{~d}$, whereas synthesis of the same compound by traditional stepwise procedures would take significantly longer. Protocols for the synthesis of thioglycoside building blocks 3 and 4 are also described.
\end{abstract}

\section{INTRODUCTION}

The emerging field of glycomics aims to expand our understanding of the function of glycans in cellular communication, protein structure and function, and human disease. Among the prerequisites for the development of glycomics is a robust and general method for synthesizing complex oligosaccharides. This can be compared to the fields of genomics and proteomics, which were pre-dated and made possible by the invention of automated methods for synthesis of polynucleotides, peptides and proteins. Although the structural and stereochemical complexity of oligosaccharides makes the development of synthetic methods more difficult, significant progress has been made toward the goal of making synthetic oligosaccharides readily available to the research community. Here, we describe a typical protocol for programmed reactivity-based one-pot synthesis of a complex glycan, using fucosyl GM1 hexasaccharide (1) as an example. Fucosyl GM1 is specifically associated with small-cell lung cancer and is therefore a target for vaccine development. This protocol serves to illustrate the methodology of programmable reactivity-based one-pot oligosaccharide synthesis ${ }^{1}$, which we have used to prepare a wide variety of oligosaccharides $^{2-7}$.

The approach is based on the observation that the protecting groups attached to a particular glycosyl donor greatly affect its rate of reactivity, with relative rates ranging over several orders of magnitude ${ }^{1,8}$. By compiling a database of relative reactivity values (RRVs) for a large library of glycosyl donors and developing an algorithm to rank the suitability of specific donor molecules for the synthesis of a given oligosaccharide target, we have made it possible to program a synthetic protocol that can be performed in a single pot, without the need to isolate intermediates or to unmask protecting groups. Although the complete database and computer program are proprietary, it is relatively straightforward to determine RRVs of glycosyl donors experimentally, as described in Box 1. The relative rates are determined by HPLC analysis of a competition assay between the glycosyl donor of interest and a reference donor of known RRV. In addition, general trends in reactivity have emerged to guide the design of an effective synthetic strategy. For instance, electron-donating protecting groups such as the benzyl ethers in 3 increase donor reactivity, whereas electronwithdrawing groups such as the acetate esters in $\mathbf{4}$ decrease reactivity. In fact, the chemical shift of the donor's anomeric proton, which is sensitive to local electron density, correlates very well with its RRV ${ }^{1}$. The identity of the sugar is also predictive, with the general RRV pattern being fucose $>$ galactose $>$ glucose $>$ mannose.

Several types of glycosyl donors have been developed over the years. Thioglycosides, first used by Garegg ${ }^{9}$, are among the most versatile because they are stable and can be activated by a wide variety of different reagents. Therefore, our relative reactivity database was generated using thioglycoside donors ${ }^{1}$. We also chose tolyl thioglycosides as building blocks because the leaving group tolyl thiol is chromogenic and the RRV can easily be determined by HPLC, measuring UV absorbance. Several thioglycoside donor activation reagents have been investigated, including $N$-iodosuccinimide-triflic acid (NIS-TfOH) $)^{10}, N$-(phenylthio)- $\varepsilon$ caprolactam-triflic anhydride ${ }^{11}$ and 1-benzenesulfinylpiperidinetriflic anhydride $\left(\mathrm{BSP}-\mathrm{Tf}_{2} \mathrm{O}\right)^{12}$. The effort to develop new activation reagents is driven by the difficulty in finding a single general reagent that provides high yield and good $\alpha / \beta$-selectivity for all substrates. The activation method employed in this protocol is $\mathrm{BSP}-\mathrm{Tf}_{2} \mathrm{O}$, which usually works very well in our hands. The scheme for preparation of the thioglycoside building blocks 3 and $\mathbf{4}$ is shown in Figure 1, and detailed protocols for synthesis of these building blocks are described in Box 2. The scheme for one-pot assembly of $\mathbf{1}$ is shown in Figure 2. For the sake of brevity, the reader is referred to the original publication ${ }^{4}$ and the supporting information included therein for preparation of trisaccharide acceptor 5. Similar to the case of peptide synthesis, some oligosaccharides are more difficult to assemble in high yield than others-for instance, in cases of steric congestion. In these difficult cases, one-pot synthesis may not be optimal because of the difficulty of purifying the final product obtained in lower yield from the abundance of byproducts and unreacted starting material also present in the reaction mixture. In such cases, traditional stepwise methods, although more time-consuming, may give 


\section{BOX 1 | GENERAL PROCEDURE FOR DETERMINING RELATIVE REACTIVITY VALUE (RRV) OF THIOGLYCOSIDE DONORS}

1. In a $10 \mathrm{ml}$ round-bottomed flask, combine the two thioglycoside donors ( $0.01 \mathrm{mmol}$ of each; $\mathbf{D}_{\text {ref }}$ is the reference donor with known RRV and $\mathbf{D}_{x}$ is the donor molecule of unknown RRV), absolute methanol ( $\left.0.05 \mathrm{mmol}\right)$ and molecular sieves AW-300 in dichloromethane (1.0 ml), and stir at room temperature for $10 \mathrm{~min}$.

2. Remove an aliquot of the mixture from Step $1(30 \mu \mathrm{l})$ and inject $10 \mu \mathrm{l}$ onto an HPLC to determine the time $=0$ absorbance $\left(A_{x}\right)_{0}$ and $\left(A_{\text {ref }}\right)_{0}$ at $254 \mathrm{~nm}$ at the initial concentration of the donor molecules [D]. The HPLC conditions must allow baseline separation of $\mathbf{D}_{\text {ref }}$ and $\mathbf{D}_{x}$. The elution gradient may be modified as needed.

3. Add a solution of $0.5 \mathrm{M}$ NIS in acetonitrile $(20 \mu \mathrm{l}, 0.01 \mathrm{mmol})$ into the above mixture, followed by addition of a solution of $0.1 \mathrm{M} \mathrm{TfOH} \mathrm{(10} \mu \mathrm{l}$, $0.001 \mathrm{mmol}$ ), and stir the mixture at room temperature for $2 \mathrm{~h}$.

4. Dilute the reaction mixture with dichloromethane $(2.0 \mathrm{ml})$, filter, wash with saturated aqueous sodium thiosulfate containing $10 \%$ sodium hydrogen carbonate, dry over sodium sulfate and concentrate to dryness on a rotary evaporator.

5. Dissolve the residue in dichloromethane $(1.0 \mathrm{ml})$ and determine absorbance at $254 \mathrm{~nm}$ of the remaining unreacted donors $\left(A_{x}\right)_{t}$ and $\left(A_{\text {ref }}\right)_{t}$ by HPLC using the same conditions ( $10 \mu \mathrm{l}$ for each injection) as determined for the mixture before the addition of reagents in Step 2.

6. Calculate the ratio of RRVs for $\mathbf{D}_{x}$ and $\mathbf{D}_{\text {ref }}, k_{x} / k_{\text {ref }}$, by applying the HPLC absorbance values from Steps 2 and 5 to the formula $k_{x} / k_{\text {ref }}=$ $\ln \left(A_{x}\right)_{t}-\ln \left(A_{x}\right)_{0} / \ln \left(A_{\text {ref }}\right)_{t}-\ln \left(A_{\text {ref }}\right)_{0}$.

better results because they allow for purification of intermediates at each step.

The protecting groups on the disaccharide glycosyl acceptor 4 were selected such that the rate of the undesired self-reaction of two molecules of 4 would be approximately 25 times slower than the rate of reaction with donor 3 (RRV 2,839 versus 72,000). After completion of the first glycosylation, the trisaccharide intermediate is reacted with trisaccharide acceptor $\mathbf{5}$ in the same pot, without purification of the intermediate, to produce fully elaborated hexasaccharide $\mathbf{2}$. Trisaccharide $\mathbf{5}$ does not have a thioglycoside function on the reducing end and therefore cannot react as a glycosyl donor under these conditions (RRV $=0)$. A series of standard deprotection steps produces the final product 1 . First, zinc $(\mathrm{Zn})$ dust in the presence of acetic anhydride converts the trichloroethyl carbamate (Troc) into an $\mathrm{N}$-acetyl group on glucosamine, then the acetate and sialic acid methyl esters are deprotected with sodium methoxide and sodium hydroxide, respectively. Finally, the benzyl groups and side-chain benzyl carbamate are deprotected by palladium (Pd)-catalyzed hydrogenolysis, and silica gel chromatography provides $\mathbf{1}$ in $21 \%$ overall yield from compounds 3 and 4 .

\section{MATERIALS}

\section{REAGENTS}

- L-Fucose (Sigma-Aldrich, cat. no. F2252)

- Pyridine (Sigma-Aldrich, cat. no. 270970) ! CAUTION Highly flammable and harmful (see material safety data sheet at http://www.sigmaaldrich.com/ catalog/search/ProductDetail/ALDRICH/270970).

- $p$-Toluenethiol (Fluka, cat. no. 88860) ! CAUTION Corrosive and has a strong smell; always work with it in a fume hood (see material safety data sheet at http://www.sigmaaldrich.com/catalog/search/ProductDetail/FLUKA/ 88860).

- Boron trifluoride diethyl etherate (Sigma-Aldrich, cat. no. 175501) 』 CAUTION Toxic (see material safety data sheet at http://www.sigmaaldrich.com/ catalog/search/ProductDetail/ALDRICH/175501).

- N,N-dimethylformamide (DMF; Aldrich, cat. no. 227056) ! CAUTION Toxic (see material safety data sheet at http://www.sigmaaldrich.com/ catalog/search/ProductDetail/ALDRICH/227056).

- Benzyl bromide (Aldrich, cat. no. B17905)

! CAUTION Irritant (see material safety data sheet at http://www.sigmaaldrich.com/catalog/search/ ProductDetail/ALDRICH/B17905).

- $60 \%$ sodium hydride (Sigma-Aldrich, cat. no. 452912) ! CAUTION Highly flammable and irritant (see material safety data sheet at http:// www.sigmaaldrich.com/catalog/search/ ProductDetail/ALDRICH/452912).

- $N$-iodosuccinimide (Aldrich, cat. no. 220051) ! CAUTION Harmful (see material safety data sheet at http://www.sigmaaldrich.com/catalog/ search/ProductDetail/ALDRICH/220051).

- Hydrazine hydrate (Sigma-Aldrich, cat. no.

225819) ! CAUTION Toxic and dangerous for the

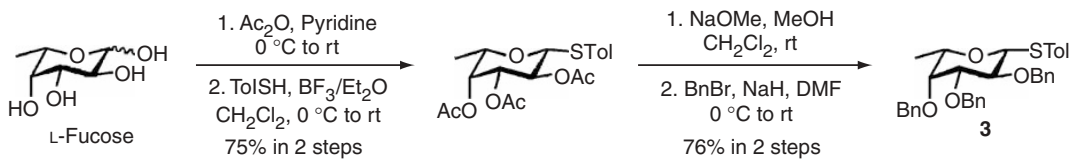

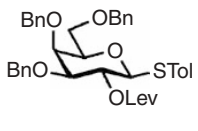

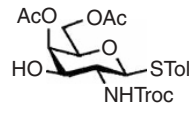

7
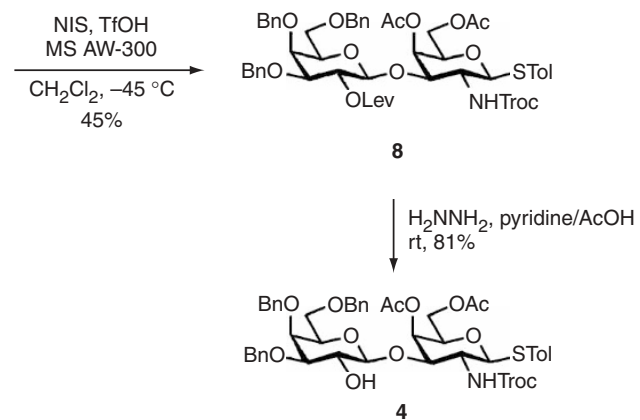

Figure 1 | Scheme for synthesis of glycosyl donor building blocks $\mathbf{3}$ and $\mathbf{4}$. 


\section{BOX 2 | PREPARATION OF THIOGLYCOSIDE BUILDING BLOCKS 3 AND 4}

Synthesis of fucosyl thioglycoside (3)

1. Weigh $2 \mathrm{~g}$ (12.18 mmol, 1.0 equiv.) L-fucose into a $100 \mathrm{ml}$ round-bottomed flask containing a Teflon-coated magnetic stir bar and cap with a rubber septum attached to a nitrogen inlet as described in detail in Step 6 of the main procedure. Turn the magnetic stirrer on.

2. Transfer $20 \mathrm{ml}$ anhydrous pyridine into a flask using a plastic syringe fitted with a 20-gauge hypodermic needle. Cool the flask to $0{ }^{\circ} \mathrm{C}$ in a ice/water bath.

3. Add $14 \mathrm{ml}$ acetic anhydride into the reaction flask using a plastic syringe fitted with a 20-gauge hypodermic needle and allow the temperature to increase gradually to room temperature. Stir at room temperature for $12 \mathrm{~h}$.

Note: Can be left overnight at room temperature.

4. Evaporate the solvent using a rotary evaporator under aspirator vacuum.

5. Dilute the residue with $20 \mathrm{ml}$ dichloromethane and transfer the resulting solution into a separatory funnel.

6. Wash the dichloromethane solution with $20 \mathrm{ml} \mathrm{H}_{2} \mathrm{O}$.

7. Separate the organic layer and extract the aqueous phase with $20 \mathrm{ml}$ dichloromethane.

8. Combine the dichloromethane layers and wash the solution with $1 \mathrm{~N} \mathrm{HCl}(2 \times 20 \mathrm{ml})$ and then with saturated sodium hydrogen carbonate $(2 \times 20 \mathrm{ml})$.

9. Dry the dichloromethane phase by addition of $3 \mathrm{~g}$ sodium sulfate and filter the mixture under gravity through a fluted filter paper on a funnel to remove sodium sulfate and collect the filtrate in a flask.

10. Evaporate the dichloromethane using a rotary evaporator at room temperature under aspirator vacuum. Dry the residue under reduced pressure to give $\alpha, \beta$-L-fucopyranosyl tetraacetate as a thick syrup.

11. Fill the flask with argon gas; remove from vacuum manifold. Add a Teflon-coated magnetic stir bar into the flask and cap with a rubber septum.

12. Weigh $1.8 \mathrm{~g}$ (14.44 mmol, 1.2 equiv.) $p$-toluenethiol into the flask; re-cap with a rubber septum attached to the nitrogen inlet. Turn the magnetic stirrer on.

13. Transfer $15 \mathrm{ml}$ dry, freshly distilled dichloromethane into the flask with a dry glass syringe fitted with a 20-gauge hypodermic needle. Cool the flask to $0{ }^{\circ} \mathrm{C}$ in a ice/water bath.

14. Dispense $3.1 \mathrm{ml}(24.07 \mathrm{mmol}, 2.0$ equiv.) boron trifluoride diethyl etherate dropwise into the flask using a dry glass syringe fitted with a 20-gauge hypodermic needle and allow the temperature to increase gradually to room temperature. Stir at room temperature for $10 \mathrm{~h}$.

Note: Can be left overnight at room temperature.

15. Dilute the mixture with $15 \mathrm{ml}$ dichloromethane. Cool the flask to $0{ }^{\circ} \mathrm{C}$ in a ice/water bath and neutralize the solution by adding saturated aqueous sodium hydrogen carbonate.

16. Transfer the resulting solution into a separatory funnel. Separate the organic layer and wash the dichloromethane solution with water $(1 \times 30 \mathrm{ml})$.

17. Dry the dichloromethane phase by adding $5 \mathrm{~g}$ sodium sulfate and filter the mixture under gravity through a fluted filter paper on a funnel to remove sodium sulfate and collect the filtrate in a flask.

18. Evaporate the dichloromethane using a rotary evaporator at room temperature under aspirator vacuum.

19. Pack a chromatography column $(4.0 \mathrm{~cm}$ i.d. $\times 25 \mathrm{~cm}$ length) with silica gel using a 4:1 (vol/vol) mixture of hexanes and ethyl acetate. 20. Load the crude mixture from Step 18 on the top of the silica bed and then cover the top of the column further with a layer of sand (approximately $0.5 \mathrm{~cm}$ thick).

21. Elute the products with a $4: 1$ ( $\mathrm{vol} / \mathrm{vol})$ mixture of hexanes and ethyl acetate and collect fractions of $25 \mathrm{ml}$.

22. Identify fractions containing $\beta$-fucosyl thioglycoside by silica gel TLC, developing with a 2:1 (vol/vol) mixture of hexanes and ethyl acetate $\left(R_{\mathrm{f}}=0.34\right)$. Products are visualized by UV absorbance at $254 \mathrm{~nm}$.

23. Collect the fractions and evaporate the solvent using a rotary evaporator. Dry the residue under reduced pressure to give $3.57 \mathrm{~g} \beta$-fucosyl thioglycoside (75\% in two steps) as white foam.

24. Add a Teflon-coated magnetic stir bar into the flask containing the residue from Step 23 and cap with a rubber septum attached to the argon inlet. Turn the magnetic stirrer on.

25. Transfer $20 \mathrm{ml} \mathrm{1:1} \mathrm{(vol/vol)} \mathrm{mixture} \mathrm{of} \mathrm{methanol} \mathrm{and} \mathrm{dichloromethane} \mathrm{into} \mathrm{the} \mathrm{flask} \mathrm{using} \mathrm{a} \mathrm{glass} \mathrm{syringe} \mathrm{fitted} \mathrm{with} \mathrm{a} \mathrm{20-gauge} \mathrm{hypodermic}$ needle.

26. Dispense $0.2 \mathrm{~mL} 25 \%$ solution of sodium methoxide in methanol into the reaction flask at room temperature using a plastic syringe fitted with a 20-gauge hypodermic needle. Stir at room temperature for $2 \mathrm{~h}$.

27. Add Amberlite IRC-50 acidic resin into the flask to neutralize the reaction until the $\mathrm{pH}$ is approximately 7.

28. Remove Amberlite IRC-50 acidic resin through a filter funnel attached to a $100 \mathrm{ml}$ round-bottomed flask and rinse with methanol.

29. Evaporate the solvent using a rotary evaporator under aspirator vacuum to give $2.35 \mathrm{~g}(97 \%)$ of the deacetylated residue.

30. Add a Teflon-coated magnetic stir bar into the flask containing the residue from Step 29 and cap with a rubber septum attached to the argon inlet. Turn the magnetic stirrer on.

31. Transfer $20 \mathrm{ml}$ anhydrous DMF and $6.2 \mathrm{ml}(52.16 \mathrm{mmol}, 6$ equiv.) benzyl bromide into the flask using a plastic syringe fitted with a 20-gauge hypodermic needle. Cool the reaction flask to $0{ }^{\circ} \mathrm{C}$ in a ice/water bath.

32. Add $1.25 \mathrm{~g} \mathrm{(31.29} \mathrm{mmol,} 3.6$ equiv.) $60 \%$ sodium hydride into the reaction flask and allow the temperature to increase gradually to room temperature. Continue stirring for $3 \mathrm{~h}$ at room temperature.

33. Quench the reaction with $3 \mathrm{ml}$ methanol and dilute the mixture with $20 \mathrm{ml}$ ethyl acetate.

34. Transfer the resulting mixture into a separatory funnel and wash with $40 \mathrm{ml}$ water. Extract the aqueous layer with additional ethyl acetate $(2 \times 20 \mathrm{ml})$. 


\section{BOX 2 | PREPARATION OF THIOGLYCOSIDE BUILDING BLOCKS 3 AND 4 (CONTINUED)}

35. Combine the ethyl acetate layers and wash with $30 \mathrm{ml}$ saturated aqueous sodium chloride (brine). Dry the ethyl acetate solution by adding $5 \mathrm{~g}$ magnesium sulfate and filter the mixture under gravity through a fluted filter paper on a funnel to remove magnesium sulfate and collect the filtrate in a flask.

36. Evaporate the solvent using a rotary evaporator under aspirator vacuum.

37. Pack a chromatography column $(4.0 \mathrm{~cm}$ i.d. $\times 20 \mathrm{~cm}$ length) with silica gel using an $8: 1$ (vol/vol) mixture of hexanes and ethyl acetate. 38. Load the crude mixture from Step 36 on the top of the silica bed and then cover the top of the column further with a layer of sand (approximately $0.5 \mathrm{~cm}$ thick).

39. Elute the products with an 8:1 ( $\mathrm{vol} / \mathrm{vol}$ ) mixture of hexanes and ethyl acetate and collect fractions of $25 \mathrm{ml}$.

40. Identify the fractions containing product 3 by silica gel TLC, developing with a 9:1 (vol/vol) mixture of hexanes and ethyl acetate $\left(R_{\mathrm{f}}=0.25\right)$. Products are visualized by UV absorbance at $254 \mathrm{~nm}$.

41. Collect the fractions and evaporate the solvent using a rotary evaporator. Dry the residue under reduced pressure to give $3.67 \mathrm{~g}$ of the $\beta$-fucosyl thioglycoside $3(78 \%)$ as a white solid.

TIMING: Step 1: 5 min; Step 2: 5 min; Step 3: 12 h; Step 4: 30 min; Steps 5-8: 30 min; Steps 9 and 10: 1 h; Steps 11 and $12: 10$ min; Step $13:$ 5 min; Step 14: 10 h; Step 15: 20 min; Step 16: 10 min; Steps 17 and 18: 1 h; Step 19: 15 min; Step 20: 10 min; Steps 21-23: 4 h; Step 24: 5 min; Step 25: 5 min; Step 26: 2 h; Steps 27-29: 1 h; Step 30: 5 min; Step 31: 10 min; Step 32: 3 h; Step 33: 10 min; Steps 34 and 35: 30 min; Step 36: 30 min; Step 37: 15 min; Step 38: 10 min; Steps 39-41: 3 h. Total for Steps 1-23: 4 d.

\section{Analytical data}

${ }^{1} \mathrm{H}$ NMR $\left(500 \mathrm{MHz}, \mathrm{CDCl}_{3}\right) \delta$ 7.50-7.48 (m, 2H), 7.40-7.27 (m, 15H), $7.01(\mathrm{~d}, \mathrm{~J}=8.1 \mathrm{~Hz}, 2 \mathrm{H}), 5.00(\mathrm{~d}, \mathrm{~J}=11.8 \mathrm{~Hz}, 1 \mathrm{H}), 4.80(\mathrm{~d}, J=10.3 \mathrm{~Hz}$, $1 \mathrm{H}), 4.73-4.71(\mathrm{~m}, 3 \mathrm{H}), 4.66(\mathrm{~d}, J=11.8 \mathrm{~Hz}, 1 \mathrm{H}), 4.54(\mathrm{~d}, J=9.6 \mathrm{~Hz}, 1 \mathrm{H}), 3.89(\mathrm{t}, J=9.6 \mathrm{~Hz}, 1 \mathrm{H}), 3.62-3.61(\mathrm{~m}, 1 \mathrm{H}), 3.58(\mathrm{dd}, J=9.6,3.0$ $\mathrm{Hz}, 1 \mathrm{H}), 3.52-3.48(\mathrm{~m}, 1 \mathrm{H}), 2.29(\mathrm{~s}, 3 \mathrm{H}), 1.25(\mathrm{~d}, \mathrm{~J}=6.2 \mathrm{~Hz}, 3 \mathrm{H})$;

HRMS $(\mathrm{m} / \mathrm{z})\left[\mathrm{M}_{+} \mathrm{Na}^{+}\right]$calcd for $\mathrm{C}_{34} \mathrm{H}_{36} \mathrm{O}_{4} \mathrm{SNa}(\mathrm{M}+\mathrm{Na})^{+}, 563.2226$; found 563.2220 .

- Trifluoromethanesulfonic anhydride $\left(\mathrm{Tf}_{2} \mathrm{O}\right.$; Sigma-Aldrich, cat. no. 176176) I CAUTION Corrosive (see material safety data sheet at http:// www.sigmaaldrich.com/catalog/search/ProductDetail/ALDRICH/176176).

- Molecular sieves (pellets, AW-300, 1.6 mm; Sigma-Aldrich, cat. no. 334324)

I CAUTION Irritant (see material safety data sheet at http://

www.sigmaaldrich.com/catalog/search/ProductDetail/ALDRICH/334324).

- Zn dust (Aldrich, cat. no. 324930) ! CAUTION Highly flammable (see material safety data sheet at http://www.sigmaaldrich.com/catalog/search/ ProductDetail/ALDRICH/324930).

- Acetic anhydride (Sigma-Aldrich, cat. no. 242845) ! CAUTION Corrosive (see material safety data sheet at http://www.sigmaaldrich.com/catalog/search/ ProductDetail/SIAL/242845).

$\cdot 25 \%$ solution of sodium methoxide in methanol (Sigma-Aldrich, cat. no. 156256) ! CAUTION Highly flammable and toxic (see material safety data sheet at http://www.sigmaaldrich.com/catalog/search/ ProductDetail/SIAL/ 156256).

-Amberlite IRC-50 hydrogen form (Sigma-Aldrich, cat. no. 428833)

- Pd-black (Sigma-Aldrich, cat. no. 520810) ! CAUTION Highly flammable (see material safety data sheet at http://www.sigmaaldrich.com/catalog/ search/ProductDetail/ALDRICH/520810).

- Hydrogen gas cylinder (Airgas)

- Silica gel 40-60 $\mu \mathrm{M}$ mesh (EMD)

- Iatro beads (Mitsubishi Kagaku Iatron, Inc., cat. no. 6RS-8060)

- Anhydrous sodium sulfate (Fisher)

- Anhydrous magnesium sulfate (Fisher)

- Sodium thiosulfate (Fisher)

- Sodium hydrogen carbonate (Fisher)

- Dichloromethane (freshly distilled over calcium hydride)

- Methanol, extra dry over molecular sieve (Acros, cat. no. 36439-0010)

- Ethyl acetate (EMD)

- Toluene (EMD)

- Acetone (EMD)

- Acetonitrile (EMD)
- Isopropyl alcohol (EMD)

- Diethyl ether (Fisher)

- Triethylamine (EMD)

- Tetrahydrofuran (EMD)

- Celite filter agent (Fisher)

- Hydrochloric acid (Fisher)

- Sodium hydroxide (Fisher)

- Formic acid (Aldrich, cat. no. 399388) ! CAUTION Corrosive (see material safety data sheet at http://www.sigmaaldrich.com/catalog/search/

ProductDetail/ALDRICH/399388).

EQUIPMENT

- Coffee mill (Bunn)

- Vacuum pump (Welch)

-Vacuum manifold with argon bubbler (Chemglass)

- Propane torch (Bernz-O-Matic)

- Dewar flask (Chemglass)

- Teflon-coated magnetic stir bars (Sigma-Aldrich)

- Glass polypropylene syringes (Hamilton) or disposable polypropylene syringes (VWR)

- Reusable hypodermic syringe needles (Hamilton) or disposable syringe needles (VWR)

- Hand-held UV lamp (UVP)

- Rotary evaporator (Büchi)

- Pyrex chromatography column (Chemglass)

- NMR tubes (Kontes)

- NMR spectrometer (Bruker DRX-500 or DRX-600)

- Filter paper (Fisher, cat. no. 09-801C)

- Balloons (Sigma-Aldrich)

- Silica gel $60 \mathrm{~F}_{254}$ thin-layer chromatography (TLC) plates (EMD Chemicals, Inc., cat. no. M5715-7)

$\cdot \mathrm{pH}$ indicator strips (Fisher)

- HPLC (Hitachi LaChrom Elite) fitted with an analytical reverse phase column (Vydac)

\section{PROCEDURE}

\section{Synthesis of protected Fuc-GM1 (2)}

1) Remove BSP from refrigerator $\left(4^{\circ} \mathrm{C}\right)$ and allow it to warm to room temperature.

2| Grind molecular sieve AW-300 pellets into powder using a coffee mill. 
3| Weigh $0.75 \mathrm{~g}$ powdered molecular sieves AW-300 into a $25 \mathrm{ml}$ round-

bottomed flask containing a

Teflon-coated magnetic stir bar.

4| Put the flask under vacuum (approximately $0.3 \mathrm{~mm} \mathrm{Hg}$ ) and flamedry it using a propane torch, then allow the flask to cool to room temperature while still under vacuum. It may be left under vacuum overnight if desired.

5| Fill the flask with argon gas, remove from vacuum manifold and cap with a rubber septum.

6| Weigh $92 \mathrm{mg}(0.17 \mathrm{mmol}, 1.06$ equiv.) fucosyl donor $3,160 \mathrm{mg}(0.16$ mmol, 1.0 equiv.) disaccharide building block 4 (Box 3) and $18 \mathrm{mg}(0.088$ mmol, 0.55 equiv.) BSP into the flask; re-cap with the septum, attached to an argon inlet with a syringe needle through the septum. The flow of argon into the flask is monitored by attaching a bubbler to the argon line through the vacuum manifold. Maintain positive argon flow throughout Steps 6-13. Turn the magnetic stirrer on.

7| Transfer $2 \mathrm{ml}$ dry, freshly distilled dichloromethane into the flask with a dry glass syringe fitted with a 20-gauge hypodermic needle.

8| Pre-dry the reaction mixture at room temperature under positive argon flow for $1 \mathrm{~h}$, as described in Step 6, and then cool the flask to $-70^{\circ} \mathrm{C}$ in a dry ice/isopropyl alcohol bath contained in the Dewar flask, while maintaining argon flow into the flask.

9| Add $16 \mu \mathrm{l}\left(0.096 \mathrm{mmol}, 0.6\right.$ equiv.) $\mathrm{Tf}_{2} 0$ into the reaction flask using a syringe and allow the temperature to increase gradually from $-70{ }^{\circ} \mathrm{C}$ to $-10{ }^{\circ} \mathrm{C}$ over $1.5 \mathrm{~h}$ by allowing the dry ice to evaporate.

$\triangle$ CRITICAL STEP The success of this step depends on the temperature of the reaction. To prevent over-reaction, the temperature should not be allowed to increase above $-5^{\circ} \mathrm{C}$. If the temperature rises too quickly, add more dry ice to the Dewar.

10| After donor 3 is consumed (as monitored by TLC, developing with hexane/ethyl acetate (2.5/1) and visualizing by UV absorbance at $254 \mathrm{~nm}$ ), cool the reaction flask to $-70{ }^{\circ} \mathrm{C}$ again. Samples for TLC analysis can be obtained without disrupting the reaction by inserting a glass capillary through a disposable syringe needle passed through the septum and dipping the capillary into the solution. TLC analysis can be performed every $30 \mathrm{~min}$ to monitor the progress of the reaction.

11. Weigh $0.34 \mathrm{~g}$ trisaccharide acceptor 5 (0.22 mmol, 1.4 equiv.) and $17 \mathrm{mg}(0.08 \mathrm{mmol}, 0.5$ equiv.) BSP into the flask; re-cap with the septum, under a positive argon flow.

12 Dispense $15 \mu \mathrm{l}\left(0.088 \mathrm{mmol}, 0.55\right.$ equiv.) $\mathrm{Tf}_{2} 0$ into the flask using a syringe, then increase the temperature gradually from $-70{ }^{\circ} \mathrm{C}$ to $0{ }^{\circ} \mathrm{C}$ as in Step 9 . Then continue stirring at $0{ }^{\circ} \mathrm{C}$ for an additional $4 \mathrm{~h}$ in an ice/water bath.

13| Transfer $0.2 \mathrm{ml}$ triethylamine into the flask to quench the reaction, and remove the flask from the cooling bath.

14 Add $3 \mathrm{ml}$ dichloromethane (does not have to be distilled) into the flask to dilute the reaction, and remove the molecular sieves AW-300 through a filter funnel attached to a $25 \mathrm{ml}$ round-bottomed flask. 


\section{BOX 3 | SYNTHESIS OF THE DISACCHARIDE BUILDING BLOCK PRECURSOR (4)}

1. Grind molecular sieve AW-300 pellets into powder using a coffee mill.

2. Weigh $0.75 \mathrm{~g}$ powdered molecular sieves AW-300 into a $25 \mathrm{ml}$ round-bottomed flask containing a Teflon-coated magnetic stir bar.

3. Put the flask under vacuum (approximately $0.3 \mathrm{~mm} \mathrm{Hg}$ ) and dry using a propane torch. Allow the flask to cool to room temperature while still under vacuum. It may be left under vacuum overnight if necessary.

4. Fill the flask with argon gas, remove from vacuum manifold and cap with a rubber septum.

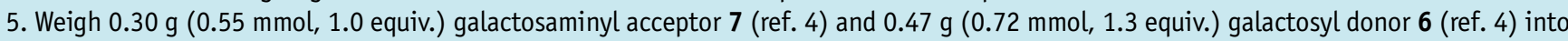
the flask; re-cap with the septum attached to an argon inlet. Turn the magnetic stirrer on.

6. Transfer $3 \mathrm{ml}$ dry, freshly distilled dichloromethane into the flask with a dry glass syringe fitted with a 20-gauge hypodermic needle.

7. Pre-dry the reaction mixture at room temperature under argon for $1 \mathrm{~h}$, and then cool the flask to $-45^{\circ} \mathrm{C}$ in a dry ice/acetonitrile bath contained in the Dewar flask.

8. Add $0.16 \mathrm{~g}(0.72 \mathrm{mmol}, 1.3$ equiv. $) \mathrm{N}$-iodosuccinimide into the reaction flask; re-cap with the septum attached to an argon inlet.

9. Dispense $144 \mu \mathrm{l}(0.072 \mathrm{mmol}, 0.13$ equiv.) freshly prepared $0.5 \mathrm{M}$ solution of trifluoromethanesulfonic acid in ether into the reaction flask using a syringe. Continue stirring for $3 \mathrm{~h}$ at $-45^{\circ} \mathrm{C}$.

The $0.5 \mathrm{M}$ solution of trifluoromethanesulfonic acid in ether is prepared as follows: add $40 \mu \mathrm{l} \mathrm{Tf} \mathrm{F}_{2} 0$ into a $250: 1$ (vol/vol) mixture of ether $(1.0 \mathrm{ml})$ and water $(4.0 \mu \mathrm{l})$; shake the mixture for a few seconds.

10. Add saturated aqueous sodium hydrogen carbonate to neutralize the reaction until the pH is approximately 7 .

11. Add solid sodium thiosulfate into the flask and keep stirring until the solution becomes colorless.

12. Remove the molecular sieves AW-300 through a filter funnel attached to a $50 \mathrm{ml}$ round-bottomed flask.

13. Transfer the filtrate into a separatory funnel and separate the organic and aqueous layers.

14. Wash the dichloromethane solution with saturated aqueous sodium hydrogen carbonate $(1 \times 5 \mathrm{ml})$, water $(1 \times 5 \mathrm{ml})$ and saturated aqueous sodium chloride (brine) $(1 \times 5 \mathrm{ml})$ sequentially.

15. Dry the dichloromethane solution by adding $1 \mathrm{~g}$ anhydrous sodium sulfate, filter the mixture under gravity through a fluted filter paper on a funnel to remove sodium sulfate and collect the filtrate in a round-bottomed flask.

16. Evaporate the dichloromethane using a rotary evaporator at room temperature under aspirator vacuum.

Note: The crude product can be stored at room temperature indefinitely.

17. Pack a chromatography column $(2.0 \mathrm{~cm}$ i.d. $\times 20 \mathrm{~cm}$ length) with silica gel using a 1:2 (vol/vol) mixture of ethyl acetate and hexanes. 18. Load the crude mixture from Step 16 on the top of the silica bed and then cover the top of the column further with a layer of sand (approximately $0.5 \mathrm{~cm}$ thick).

19. Elute the products with a 1:2 ( $\mathrm{vol} / \mathrm{vol})$ mixture of ethyl acetate and hexanes and collect fractions of $8 \mathrm{ml}$.

20. Identify fractions containing the protected disaccharide building block precursor 8 by silica gel TLC, developing with a 2:3 (vol/vol) mixture of ethyl acetate and hexanes $\left(R_{\mathrm{f}}=0.28\right)$. Products are visualized by UV absorbance at $254 \mathrm{~nm}$.

21. Collect the fractions and evaporate the solvent using a rotary evaporator. Dry the residue under reduced pressure to give $0.27 \mathrm{~g}$ disaccharide building block precursor $8(45 \%)$ as a white glassy solid.

Note: Purified compound 8 can be stored at room temperature indefinitely.

22. Weigh $0.27 \mathrm{~g}$ disaccharide precursor $8(0.25 \mathrm{mmol}, 1.0$ equiv. $)$ into a $25 \mathrm{ml}$ round-bottomed flask containing a Teflon-coated magnetic stir bar. Turn the magnetic stirrer on.

23. Transfer $3 \mathrm{ml}$ pyridine into the flask with a plastic syringe fitted with a 20-gauge hypodermic needle.

24. Add $0.75 \mathrm{ml}$ ( $0.75 \mathrm{mmol}, 3.0$ equiv.) $1 \mathrm{M}$ solution of hydrazine hydrate in pyridine/acetic acid mixture into the reaction flask using a syringe. Continue the stirring at room temperature for $4 \mathrm{~h}$.

The $1 \mathrm{M}$ solution of hydrazine hydrate in pyridine/acetic acid mixture is prepared as follows: add 0.3 ml hydrazine hydrate into a mixture of $2.6 \mathrm{ml}$ pyridine and $1.9 \mathrm{ml}$ acetic acid; shake the mixture for a few seconds.

25. Dispense $1.0 \mathrm{ml}$ 2,4-pentanedione into the reaction flask to quench the excess hydrazine hydrate.

26. Evaporate the solvent using a rotary evaporator under aspirator vacuum.

27. Dilute the residue from Step 27 with $5 \mathrm{ml}$ dichloromethane and wash the resulting solution with water $(1 \times 5 \mathrm{ml})$ and brine $(1 \times 5 \mathrm{ml})$. 28. Dry the dichloromethane solution by adding of $1 \mathrm{~g}$ anhydrous sodium sulfate, filter the mixture under gravity through a fluted filter paper on a funnel to remove sodium sulfate and collect the filtrate in a round-bottomed flask.

29. Evaporate the dichloromethane using a rotary evaporator at room temperature under aspirator vacuum.

30. Pack a chromatography column $(2.0 \mathrm{~cm}$ i.d. $\times 12 \mathrm{~cm}$ length) with silica gel using a 1:2 (vol/vol) mixture of ethyl acetate and hexanes. 31. Load the crude mixture from Step 30 on the top of the silica bed and then cover the top of the column further with a layer of sand (approximately $0.5 \mathrm{~cm}$ thick).

32. Elute the products with a 1:2 ( $\mathrm{vol} / \mathrm{vol})$ mixture of ethyl acetate and hexanes and collect fractions of $8 \mathrm{ml}$.

33. Identify fractions containing the disaccharide 4 by silica gel TLC, developing with a $2: 3$ ( $\mathrm{vol} / \mathrm{vol})$ mixture of ethyl acetate and hexanes $\left(R_{\mathrm{f}}=\right.$ 0.32). Products are visualized by UV absorbance at $254 \mathrm{~nm}$.

34. Collect the fractions and evaporate the solvent using a rotary evaporator. Dry the residue under reduced pressure to give $0.20 \mathrm{~g}$ disaccharide $4(81 \%)$ as a white glassy solid.

TIMING: Disaccharide (4) Step 1: 5 min; Steps 2 and 3: 30 min; Steps 4-6: 10 min; Step 7: 1 h; Step 8: 5 min; Step 9: 3 h; Step 10: 5 min; Step 11: $10 \mathrm{~min}$; Step 12: $10 \mathrm{~min}$; Steps 13 and 14: $20 \mathrm{~min}$; Steps 15 and 16: 1 h; Step 17: 15 min; Step 18: 5 min; Steps 19-22: 3 h. Total for 


\section{BOX 3 | SYNTHESIS OF THE DISACCHARIDE BUILDING BLOCK PRECURSOR (4) (CONTINUED)}

Steps 1-22: $10 \mathrm{~h}$. Step 23: $5 \mathrm{~min}$; Step 24: $5 \mathrm{~min}$; Step 25: 4 h; Steps 26 and 27: $30 \mathrm{~min}$; Step 28: $20 \mathrm{~min}$; Steps 29 and 30: 1 h; Step 31: 15 min; Step 32: 5 min; Steps 33-35: 2 h. Total for Steps 23-35: 8.5 h.

Analytical data

Disaccharide precursor (8) ${ }^{1} \mathrm{H}$ NMR $\left(500 \mathrm{MHz}, \mathrm{CDCl}_{3}\right) \delta 7.44(\mathrm{~d}, \mathrm{~J}=8.1 \mathrm{~Hz}, 2 \mathrm{H}), 7.35-7.20(\mathrm{~m}, 15 \mathrm{H}), 7.07(\mathrm{~d}, \mathrm{~J}=8.1 \mathrm{~Hz}, 2 \mathrm{H}), 5.36(\mathrm{~d}, \mathrm{~J}=3.3$ $\mathrm{Hz}, 1 \mathrm{H}), 5.32(\mathrm{~d}, J=10.3 \mathrm{~Hz}, 1 \mathrm{H}), 5.23(\mathrm{dd}, J=10.3,8.1 \mathrm{~Hz}, 1 \mathrm{H}), 4.91(\mathrm{~d}, J=12.1 \mathrm{~Hz}, 1 \mathrm{H}), 4.87(\mathrm{~d}, J=11.8 \mathrm{~Hz}, 1 \mathrm{H}), 4.61(\mathrm{~d}, J=12.5 \mathrm{~Hz}$, $1 \mathrm{H}), 4.54(\mathrm{~d}, J=12.1 \mathrm{~Hz}, 1 \mathrm{H}), 4.53(\mathrm{~d}, J=11.8 \mathrm{~Hz}, 1 \mathrm{H}), 4.48(\mathrm{~d}, J=11.8 \mathrm{~Hz}, 1 \mathrm{H}), 4.45(\mathrm{~d}, J=12.5 \mathrm{~Hz}, 1 \mathrm{H}), 4.43(\mathrm{~d}, J=11.8 \mathrm{~Hz}, 1 \mathrm{H}), 4.37$ $(\mathrm{d}, J=7.7 \mathrm{~Hz}, 1 \mathrm{H}), 4.31(\mathrm{dd}, J=10.3,3.3 \mathrm{~Hz}, 1 \mathrm{H}), 4.09(\mathrm{dd}, J=11.7,4.4 \mathrm{~Hz}, 1 \mathrm{H}), 4.02(\mathrm{dd}, J=11.7,7.7 \mathrm{~Hz}, 1 \mathrm{H}), 3.88(\mathrm{~d}, J=2.2 \mathrm{~Hz}, 1 \mathrm{H})$, $3.80(\mathrm{dd}, J=7.7,4.4 \mathrm{~Hz}, 1 \mathrm{H}), 3.56-3.63(\mathrm{~m}, 2 \mathrm{H}), 3.49(\mathrm{dd}, \mathrm{J}=6.6,6.3 \mathrm{~Hz}, 1 \mathrm{H}), 3.45-3.42(\mathrm{~m}, 1 \mathrm{H}), 3.38(\mathrm{dd}, \mathrm{J}=10.3,2.6 \mathrm{~Hz}, 1 \mathrm{H}), 2.97$ (ddd, $J=17.6,11.0,2.6 \mathrm{~Hz}, 1 \mathrm{H}$ ), 2.86 (ddd, $J=17.6,11.0,2.6 \mathrm{~Hz}, 1 \mathrm{H}$ ), 2.47 (ddd, J=17.3, 5.5, 2.9 Hz, 1H), 2.32 (s, 3H), 2.24 (ddd, J = $17.3,5.5,2.9 \mathrm{~Hz}, 1 \mathrm{H}), 2.21(\mathrm{~s}, 3 \mathrm{H}), 2.02(\mathrm{~s}, 3 \mathrm{H}), 2.00(\mathrm{~s}, 3 \mathrm{H})$;

HRMS $(\mathrm{m} / \mathrm{z})\left[\mathrm{M}+\mathrm{Na}^{+}\right]$calcd for $\mathrm{C}_{52} \mathrm{H}_{58} \mathrm{Cl}_{3} \mathrm{NO}_{15} \mathrm{SNa}, 1096.2485$; found 1096.2491 .

Disaccharide (4) ${ }^{1} \mathrm{H} \mathrm{NMR}\left(500 \mathrm{MHz}, \mathrm{CDCl}_{3}\right) \delta 7.40-7.25(\mathrm{~m}, 17 \mathrm{H}), 7.09(\mathrm{~d}, \mathrm{~J}=7.7 \mathrm{~Hz}, 2 \mathrm{H}), 5.77(\mathrm{~d}, \mathrm{~J}=6.6 \mathrm{~Hz}, 1 \mathrm{H}), 5.32(\mathrm{~d}, J=2.6 \mathrm{~Hz}, 1 \mathrm{H})$ $4.92(\mathrm{~d}, J=11.4 \mathrm{~Hz}, 1 \mathrm{H}), 4.76-4.71(\mathrm{~m}, 5 \mathrm{H}), 4.56(\mathrm{~d}, J=11.4 \mathrm{~Hz}, 1 \mathrm{H}), 4.47(\mathrm{~d}, J=11.7 \mathrm{~Hz}, 1 \mathrm{H}), 4.44(\mathrm{~d}, J=11.7 \mathrm{~Hz}, 1 \mathrm{H}), 4.38(\mathrm{~d}, J=8.1$ $\mathrm{Hz}, 1 \mathrm{H}), 4.13-4.08(\mathrm{~m}, 3 \mathrm{H}), 3.97-3.90(\mathrm{~m}, 2 \mathrm{H}), 3.84-3.78(\mathrm{~m}, 5 \mathrm{H}), 3.73(\mathrm{t}, \mathrm{J}=6.6 \mathrm{~Hz}, 1 \mathrm{H}), 3.65-3.58(\mathrm{~m}, 4 \mathrm{H}), 3.38(\mathrm{dd}, J=9.5,2.6 \mathrm{~Hz}, 1 \mathrm{H})$, $2.32(\mathrm{~s}, 3 \mathrm{H}), 2.03(\mathrm{~s}, 6 \mathrm{H})$;

HRMS (m/z) $\left[\mathrm{M}+\mathrm{Na}^{+}\right]$calcd for $\mathrm{C}_{47} \mathrm{H}_{52} \mathrm{Cl}_{3} \mathrm{NO}_{13} \mathrm{SNa}$, 998.2117; found 998.2106 .

15| Transfer the filtrate into a separatory funnel and wash the dichloromethane solution with saturated aqueous sodium thiosulfate $(1 \times 5 \mathrm{ml})$, saturated aqueous sodium hydrogen carbonate $(1 \times 5 \mathrm{ml})$, water $(1 \times 5 \mathrm{ml})$ and saturated aqueous sodium chloride (brine) $(1 \times 5 \mathrm{ml})$ sequentially.

16| Dry the dichloromethane solution by adding approximately $1 \mathrm{~g}$ anhydrous sodium sulfate, stir for 5 min, filter the mixture under gravity through a fluted filter paper on a funnel to remove sodium sulfate and collect the filtrate in a round-bottomed flask.

17| Evaporate the dichloromethane using a rotary evaporator at room temperature under aspirator vacuum.

PAUSE POINT The crude product can be stored at $4^{\circ} \mathrm{C}$ overnight.

18| Pack a chromatography column $(1.5 \mathrm{~cm}$ i.d. $\times 30 \mathrm{~cm}$ length) with silica gel using a 1:2 (vol/vol) mixture of toluene and ethyl acetate.

19| Load the crude mixture from Step 17 on the top of the silica bed and then cover the top of the column further with a layer of sand (approximately $0.5 \mathrm{~cm}$ thick).

20| Elute the products with a 1:2 ( $\mathrm{vol} / \mathrm{vol})$ mixture of toluene and ethyl acetate, and collect fractions of 5-10 ml.

21 Identify fractions containing protected Fuc-GM1 2 by silica gel TLC, developing with a 1:2 (vol/vol) mixture of toluene and ethyl acetate $\left(R_{\mathrm{f}}=0.32\right)$. Products are visualized by UV absorbance at $254 \mathrm{~nm}$.

22 Collect the fractions and evaporate the solvent using a rotary evaporator. Dry the residue under reduced pressure to give $0.21 \mathrm{~g}$ of the protected Fuc-GM1 $2(47 \%)$ as a white glassy solid.

- PAUSE POINT Compound 2 can be stored indefinitely at $4{ }^{\circ} \mathrm{C}$ before carrying on to the deprotection steps described below.

23| Characterize the protected Fuc-GM1 2 from Step 22 by NMR spectroscopy using deuterated chloroform as solvent, referring to spectral data provided under ANTICIPATED RESULTS.

\section{Synthesis of deprotected Fuc-GM1 (1)}

24| Activate the $\mathrm{Zn}$ dust by washing sequentially with $1 \mathrm{M}$ aqueous $\mathrm{HCl}, \mathrm{H}_{2} \mathrm{O}$, methanol and diethyl ether through a filter funnel attached to a $100 \mathrm{ml}$ round-bottomed flask.

25| Transfer the freshly activated $\mathrm{Zn}$ dust into a vial and dry it under vacuum.

26| Weigh $80 \mathrm{mg}(29 \mu \mathrm{mol})$ protected Fuc-GM1 into a flask containing a Teflon-coated magnetic stir bar and cap with a rubber septum attached to the argon inlet. Turn the magnetic stirrer on.

27| Transfer $1 \mathrm{ml}$ freshly distilled dichloromethane and $1 \mathrm{ml}$ acetic anhydride into the flask with a glass syringe fitted with a 20-gauge hypodermic needle.

28| Add $1 \mathrm{~g}$ freshly activated $\mathrm{Zn}$ dust into the flask and stir the reaction at room temperature for $5 \mathrm{~h}$.

- PAUSE POINT The reaction mixture can be left at room temperature overnight. 
PROTOCOL

29| Remove the $\mathrm{Zn}$ dust by filtration through a filter funnel attached to a $25 \mathrm{ml}$ round-bottomed flask.

30| Evaporate the solvent using a rotary evaporator under aspirator vacuum.

31 Dilute the residue with $5 \mathrm{ml}$ dichloromethane and transfer the resulting solution into a separatory funnel.

32 Wash the dichloromethane solution with saturated aqueous sodium hydrogen carbonate $(1 \times 5 \mathrm{ml})$ and brine $(1 \times 5 \mathrm{ml})$.

33| Dry the dichloromethane solution by adding anhydrous sodium sulfate as in Step 16, filter the mixture under gravity through a fluted filter paper on a funnel and collect the filtrate in a flask.

34| Evaporate the dichloromethane using a rotary evaporator at room temperature under aspirator vacuum.

35| Pack a chromatography column $(1.5 \mathrm{~cm}$ i.d. $\times 30 \mathrm{~cm}$ length) with silica gel using a 3:1 (vol/vol) mixture of toluene and acetone.

36 Load the crude mixture from Step 34 on the top of the silica bed and then cover the top of the column further with a layer of sand (approximately $0.5 \mathrm{~cm}$ thick).

37| Elute the column with a 2:1 ( $\mathrm{vol} / \mathrm{vol})$ mixture of toluene and acetone.

38| Identify fractions containing desired $\mathrm{N}$-acetamido product by TLC by developing plates with 2:1 (vol/vol) mixture of toluene and acetone $\left(R_{\mathrm{f}}=0.12\right)$.

39| Collect the fractions and evaporate the solvent using a rotary evaporator. Concentrate the residue under reduced pressure.

40| Add a Teflon-coated magnetic stir bar into the flask containing the residue from Step 39 and cap with a rubber septum attached to the argon inlet, as in Step 6. The presence of water will interfere with the reaction. Turn the magnetic stirrer on.

41| Transfer $2 \mathrm{ml} \mathrm{1:1} \mathrm{(vol/vol)} \mathrm{mixture} \mathrm{of} \mathrm{anhydrous} \mathrm{methanol} \mathrm{and} \mathrm{freshly} \mathrm{distilled} \mathrm{dichloromethane} \mathrm{into} \mathrm{the} \mathrm{flask} \mathrm{using} \mathrm{a}$ glass syringe fitted with a 20-gauge hypodermic needle.

42 Dispense $50 \mu \mathrm{l} 25 \%$ solution of sodium methoxide in methanol into the reaction flask at room temperature using a syringe. Stir at room temperature for $10 \mathrm{~h}$.

- PAUSE POINT Can be left overnight at room temperature.

43 Add Amberlite IRC-50 acidic resin into the flask to neutralize the reaction until the pH is approximately 7, as determined with a pH indicator strip.

44| Remove Amberlite IRC-50 acidic resin through a filter funnel attached to a $25 \mathrm{ml}$ round-bottomed flask and rinse with methanol.

45 Evaporate the solvent using a rotary evaporator under aspirator vacuum to give the deacylated residue.

46| Add a Teflon-coated magnetic stir bar into the flask containing the residue from Step 45. Turn the magnetic stirrer on.

47| Transfer $3 \mathrm{ml} \mathrm{2:1} \mathrm{(vol/vol)} \mathrm{mixture} \mathrm{of} \mathrm{methanol} \mathrm{and} \mathrm{tetrahydrofuran} \mathrm{into} \mathrm{the} \mathrm{flask} \mathrm{using} \mathrm{a} \mathrm{plastic} \mathrm{syringe} \mathrm{fitted} \mathrm{with}$ a 20-gauge hypodermic needle.

48 Add $0.5 \mathrm{ml} 2 \mathrm{M}$ aqueous sodium hydroxide solution into the reaction flask at room temperature using a plastic syringe fitted with a 20-gauge hypodermic needle. Continue stirring for $3 \mathrm{~h}$ at room temperature.

49| Carefully add concentrated $\mathrm{HCl}$ (approximately $80 \mu \mathrm{l}$ ) into the flask to neutralize the reaction, until the pH is approximately 7, as determined with a pH indicator strip.

50| Evaporate the solvent using a rotary evaporator under aspirator vacuum.

51| Add a Teflon-coated magnetic stir bar into the flask containing the residue from Step 50. Turn the magnetic stirrer on.

52| Transfer $3 \mathrm{ml}$ solution of methanol with $10 \%$ (vol/vol) formic acid into the flask.

53| Add $70 \mathrm{mg}$ Pd-black into the reaction flask and displace the air in the flask with a balloon containing argon; then displace the argon with a balloon containing hydrogen. 
54| Stir the reaction under 1 atmospheric hydrogen (balloon full of hydrogen gas) at room temperature for $18 \mathrm{~h}$.

$\square$ PAUSE POINT Can be left overnight at room temperature.

55| Remove the balloon and add a $5 \mathrm{M}$ solution of $\mathrm{NaOH}$ in $\mathrm{H}_{2} \mathrm{O}$ into the flask to neutralize the reaction to $\mathrm{pH} 7$.

56 Remove the Pd-black by filtration through a filter funnel containing a layer of celite (approximately $3 \mathrm{~cm}$ ) attached to a $25 \mathrm{ml}$ round-bottomed flask.

57| Evaporate the solvent using a rotary evaporator under aspirator vacuum.

58| Pack a chromatography column $(1.5 \mathrm{~cm}$ i.d. $\times 15 \mathrm{~cm}$ length) with Iatro beads using a 3:4:1 ( $\mathrm{vol} / \mathrm{vol} / \mathrm{vol})$ mixture of dichloromethane, methanol and $\mathrm{H}_{2} \mathrm{O}$.

59| Load the crude mixture from Step 57 on the top of the Iatro bead bed and then cover the top of the column further with a layer of sand (approximately $0.5 \mathrm{~cm}$ thick).

60| Elute the column with a 3:4:1 ( $\mathrm{vol} / \mathrm{vol} / \mathrm{vol})$ mixture of dichloromethane, methanol and $\mathrm{H}_{2} \mathrm{O}$.

61| Identify fractions containing Fuc-GM1 1 by TLC by developing plates with a 3:4:1 (vol/vol/vol) mixture of dichloromethane, methanol and $\mathrm{H}_{2} \mathrm{O}\left(R_{\mathrm{f}}=0.1\right)$.

62| Collect the fractions and evaporate the solvent using a rotary evaporator.

63| Dissolve the residue from Step 62 in $5 \mathrm{ml} \mathrm{H} \mathrm{H}_{2} \mathrm{O}$ and transfer the solution into a $20 \mathrm{ml}$ vial.

64| Freeze the solution with liquid nitrogen and lyophilize under reduced pressure to give $15 \mathrm{mg}$ Fuc-GM1 1 (44\% over four steps) as a white solid.

\section{TIMING}

Protected Fuc-GM1 (2)

Step 1: 30 min; Step 2: 5 min; Steps 3 and 4: 30 min; Steps 5-7: 10 min; Step 8: 1 h; Step 9: 1.5 h; Steps 10 and 11: 15 min; Step 12: 6 h; Steps 13 and 14: 15 min; Step 15: 20 min; Steps 16 and 17: 30 min; Step 18: 15 min; Step 19: 5 min;

Steps 20-22: $3 \mathrm{~h}$; Step 23: $30 \mathrm{~min}$. Total for Steps 1-17: $11 \mathrm{~h}$, should be performed in a single day. Steps 18-23: $4 \mathrm{~h}$.

\section{Fuc-GM1 (1)}

Steps 24 and 25: $30 \mathrm{~min}$; Step 26: $5 \mathrm{~min}$; Step 27: $5 \mathrm{~min}$; Step 28: 5 h; Steps 29 and 30: $30 \mathrm{~min}$; Steps 31 and 32: 15 min; Step 33: 15 min; Step 34: 15 min; Step 35: 15 min; Step 36: 5 min; Steps 37-39: 2 h; Steps 40 and 41: 5 min; Step 42: 10 h; Steps 43-45: $30 \mathrm{~min}$; Steps 46 and 47: $5 \mathrm{~min}$; Step 48: 3 h; Step 49: $5 \mathrm{~min}$; Step 50: $30 \mathrm{~min}$; Steps 51 and 52: 5 min; Step 53: 10 min; Step 54: 18 h; Step 55: 5 min; Steps 56 and 57: 30 min; Step 58: 15 min; Step 59: 5 min; Steps 60-62: 3 h; Steps 63 and 64: $24 \mathrm{~h}$. Total for Steps 24-64: $3 \mathrm{~d}$.

\section{? TROUBLESHOOTING}

Troubleshooting advice can be found in Table 1.

TABLE 1 | Troubleshooting table.

\begin{tabular}{|c|c|c|}
\hline Problem & Possible reason & Solution \\
\hline Low yield of 2 & $\begin{array}{l}\text { The glycoslyation reactions are water sensitive. Moisture } \\
\text { must be rigorously avoided }\end{array}$ & $\begin{array}{l}\text { Carefully follow the procedure for drying the molecular sieves and } \\
\text { flask under vacuum. Use freshly distilled, dry dichloromethane as } \\
\text { solvent }\end{array}$ \\
\hline Low yield of 1 & $\begin{array}{l}\text { Presence of water in Steps } 40-42 \text { or old, inactive bottle } \\
\text { of Pd-black in Step } 53\end{array}$ & $\begin{array}{l}\text { Use freshly distilled dichloromethane, unopened bottles of dry } \\
\text { methanol and sodium methoxide in methanol and a new bottle } \\
\text { of Pd-black }\end{array}$ \\
\hline Low yield of 2 & $\begin{array}{l}\mathrm{Tf}_{2} \mathrm{O} \text { is water-sensitive. A previously opened bottle may } \\
\text { have undergone some hydrolysis }\end{array}$ & Use a fresh, unopened bottle of $\mathrm{Tf}_{2} \mathrm{O}$ \\
\hline $\begin{array}{l}\text { Unwanted } \\
\text { side products } \\
\text { are observed }\end{array}$ & $\begin{array}{l}\text { Over-reaction of donor with itself, or activation of product } \\
2 \text {, owing to insufficient temperature control }\end{array}$ & $\begin{array}{l}\text { Carefully maintain the temperature below the temperature indicated } \\
\text { in the protocol. Keep a supply of dry ice nearby to reduce the } \\
\text { temperature quickly if it rises above } 0{ }^{\circ} \mathrm{C}\end{array}$ \\
\hline
\end{tabular}


PROTOCOL

\section{ANTICIPATED RESULTS}

A typical yield for the one-pot glycosylation operations (Steps 1-23) is 47\%. A typical yield for the deprotection steps (Steps $24-64$ ) is $44 \%$, for a total yield of $21 \%$ of Fuc-GM1 1 from protected building blocks $3, \mathbf{4}$ and $\mathbf{5}$.

\section{Analytical data \\ Protected Fuc-GM1 (2)}

${ }^{1} \mathrm{H} \mathrm{NMR}\left(500 \mathrm{MHz}, \mathrm{CDCl}_{3}\right) \delta 7.52(\mathrm{~d}, \mathrm{~J}=7.4 \mathrm{~Hz}, 2 \mathrm{H}), 7.36-7.07(\mathrm{~m}, 63 \mathrm{H}), 5.96(\mathrm{~d}, \mathrm{~J}=8.8 \mathrm{~Hz}, 1 \mathrm{H}), 5.52-5.47(\mathrm{~m}, 2 \mathrm{H}), 5.26-5.09$ $(\mathrm{m}, 6 \mathrm{H}), 4.96-4.92(\mathrm{~m}, 2 \mathrm{H}), 4.84-4.72(\mathrm{~m}, 6 \mathrm{H}), 4.68-4.38(\mathrm{~m}, 19 \mathrm{H}), 4.33-4.29(\mathrm{~m}, 3 \mathrm{H}), 4.22-4.15(\mathrm{~m}, 4 \mathrm{H}), 4.10-3.94(\mathrm{~m}, 11 \mathrm{H})$, 3.89-3.86 (m, 2H), $3.81(\mathrm{~s}, 3 \mathrm{H}), 3.76-3.73(\mathrm{~m}, 2 \mathrm{H}), 3.67-3.62(\mathrm{~m}, 5 \mathrm{H}), 3.56-3.44(\mathrm{~m}, 10 \mathrm{H}), 3.35-3.26(\mathrm{~m}, 2 \mathrm{H}), 2.34-2.30$ $(\mathrm{m}, 1 \mathrm{H}), 2.15(\mathrm{~s}, 3 \mathrm{H}), 1.99(\mathrm{~s}, 3 \mathrm{H}), 1.97(\mathrm{~s}, 3 \mathrm{H}), 1.96(\mathrm{~s}, 3 \mathrm{H}), 1.92(\mathrm{~s}, 3 \mathrm{H}), 1.90(\mathrm{~s}, 3 \mathrm{H}), 1.88(\mathrm{~s}, 3 \mathrm{H}), 1.03(\mathrm{~s}, 3 \mathrm{H})$;

${ }^{13} \mathrm{C}$-Apt NMR $\left(150 \mathrm{MHz}, \mathrm{CDCl}_{3}\right) \delta 170.65,170.36,170.31,169.81,169.60,169.27,168.58,156.42,156.16,154.10,139.15$, $138.91,138.70,138.61,138.50,138.29,138.12,137.83,137.78,136.61,136.47,129.56,128.97,128.43,128.40,128.33$, $128.24,128.20,128.12,128.08,127.97,127.90,127.88,127.81,127.76,127.68,127.64,127.61,127.56,127.52,127.42$, $127.28,127.26,127.23,127.14,127.07,127.03,126.86,126.75,126.67,126.44,103.50,102.76,101.69,99.12,97.49$, $95.78,83.46,82.54,81.66,79.04,78.92,77.84,76.46,76.17,76.10,75.93,75.87,74.96,74.87,74.81,74.71,74.52,74.22$, $74.15,73.97,73.52,73.39,73.22,73.12,72.50,72.45,72.31,71.92,71.62,70.72,70.09,69.09,69.06,68.34,68.20,68.18$, $68.00,67.87,67.22,67.16,66.44,62.48,61.66,54.91,53.15,51.36,49.34,47.03,45.96,35.59,29.63,23.15,21.22,20.90$, $20.78,20.58,20.55,20.45,16.82$; HRMS $(m / z)\left[\mathrm{M}+\mathrm{Na}^{+}\right]$calcd for $\mathrm{C}_{151} \mathrm{H}_{168} \mathrm{Cl}_{3} \mathrm{~N}_{3} \mathrm{O}_{42} \mathrm{Na}, 2823.0060$; found 2823.0114 .

\section{Fuc-GM1 (1)}

${ }^{1} \mathrm{H}$ NMR $\left(600 \mathrm{MHz}, \mathrm{D}_{2} 0\right)^{\mathrm{TM}} 5.07(\mathrm{~d}, J=3.5 \mathrm{~Hz}, 1 \mathrm{H}), 4.51(\mathrm{~d}, J=7.5 \mathrm{~Hz}, 1 \mathrm{H}), 4.44(\mathrm{~d}, J=6.6 \mathrm{~Hz}, 1 \mathrm{H}), 4.37-4.35(\mathrm{~m}, 2 \mathrm{H}), 4.06-4.02$ $(\mathrm{m}, 1 \mathrm{H}), 3.95(\mathrm{dd}, \mathrm{J}=10.1,2.2 \mathrm{~Hz}, 1 \mathrm{H}), 3.92-3.90(\mathrm{~m}, 3 \mathrm{H}), 3.81(\mathrm{~d}, \mathrm{~J}=11.4 \mathrm{~Hz}, 1 \mathrm{H}), 3.75-3.41(\mathrm{~m}, 29 \mathrm{H}), 3.20-3.17(\mathrm{~m}, 2 \mathrm{H})$, $2.99(\mathrm{~s}, 2 \mathrm{H}), 2.50(\mathrm{dd}, \mathrm{J}=12.3,4.4 \mathrm{~Hz}, 1 \mathrm{H}), 1.85(\mathrm{~s}, 6 \mathrm{H}), 1.73(\mathrm{t}, \mathrm{J}=12.3 \mathrm{~Hz} 1 \mathrm{H}), 1.03(\mathrm{~d}, \mathrm{~J}=6.6 \mathrm{~Hz}, 3 \mathrm{H}) ;{ }^{13} \mathrm{C}-\mathrm{Apt} \mathrm{NMR}(150 \mathrm{MHz}$ $\left.\mathrm{D}_{2} 0\right)^{\mathrm{TM}} 174.56,173.80,173.54,102.76,102.14,101.68,101.58,100.89,98.70,75.99,75.39,74.44,74.34,73.65,72.57,72.29$, $71.83,71.39,69.52,69.10,68.69,68.23,67.99,67.61,66.89,66.29,62.39,60.67,60.45,60.04,59.54,51.16,51.07,39.17$, $36.86,22.27,21.60,14.92$; HRMS $(m / z)[M-H]^{-}$calcd for $\mathrm{C}_{45} \mathrm{H}_{76} \mathrm{~N}_{3} \mathrm{O}_{33}$ 1186.4366; found 1186.4619.

COMPETING INERESTS STATEMENT The authors declare that they have no competing financial interests

Published online at http://www.natureprotocols.com

Reprints and permissions information is available online at http://npg.nature.com/ reprintsandpermissions

1. Zhang, Z. et al. Programmable one-pot oligosaccharide synthesis. J. Am. Chem. Soc. 121, 734-753 (1999).

2. Burkhart, F., Zhang, Z., Wacowich-Sgarbi, S. \& Wong, C.-H. Synthesis of the Globo $\mathrm{H}$ hexasaccharide using the programmable reactivity-based one-pot strategy. Angew. Chem. Int. Ed. Engl. 40, 1274-1277 (2001).

3. Mong, K.-K.T. \& Wong, C.-H. Reactivity-based one-pot synthesis of a Lewis $Y$ carbohydrate hapten: a colon-rectal cancer antigen determinant. Angew. Chem. Int. Ed. Engl. 41, 4087-4090 (2002).

4. Mong, K.-K.T., Lee, H.-K., Duron, S.G. \& Wong, C.-H. Reactivity-based one-pot total synthesis of fucose $\mathrm{GM}_{1}$ oligosaccharide: a sialylated antigenic epitope of small-cell lung cancer. Proc. Natl. Acad. Sci. USA 100, 797-802 (2003).

5. Ritter, T.K., Mong, K.-K., Liu, H., Nakatani, T. \& Wong, C.-H. A programmable one-pot oligosaccharide synthesis for diversifying the sugar domains of natural products: a case study of vancomycin. Angew. Chem. Int. Ed. Engl. 42, 4657-4660 (2003).

6. Lee, H.-K. et al. Reactivity-based one-pot synthesis of oligomannoses: defining antigens recognized by $2 \mathrm{G} 12$, a broadly neutralizing anti-HIV-1 antibody. Angew. Chem. Int. Ed. Engl. 43, 1000-1003 (2004).
7. Lee, J.-C., Wu, C.-Y., Apon, J.V., Siuzdak, G. \& Wong, C.-H. Reactivity-based onepot synthesis of the tumor-associated antigen N3 minor octasaccharide for the development of a photocleavable DIOS-MS sugar array. Angew. Chem. Int. Ed. Engl. 45, 2753-2757 (2006).

8. Douglas, N.L., Ley, S.V., Lücking, U. \& Warriner, S.L. Tuning glycoside reactivity: new tool for efficient oligosaccharide synthesis. J. Chem. Soc. Perkin Trans. I 51-65 (1998).

9. Fugedi, P. \& Garegg, P.J. A novel promoter for the efficient construction of 1,2trans linkages in glycoside synthesis, using thioglycosides as glycosyl donors. Carbohydr. Res. 149, C9-C12 (1986).

10. Veeneman, G.H., van Leeuwen, S.H. \& van Boom, J.H. Iodonium ion promoted reactions at the anomeric centre. II. An efficient thioglycoside mediated approach toward the formation of 1,2-trans linked glycosides and glycosidic esters. Tetrahedron Lett. 31, 1331-1334 (1990).

11. Duron, S.G., Polat, T. \& Wong, C.-H. N-(Phenylthio)-e-caprolactam: a new promoter for the activation of thioglycosides. Org. Lett. 6, 839-841 (2004).

12. Crich, D. \& Smith, M. 1-Benzenesulfinyl piperidine/trifluoromethanesul fonic anhydride: a potent combination of shelf-stable reagents for the low-temperature conversion of thioglycosides to glycosyl triflates and for the formation of diverse glycosidic linkages. J. Am. Chem. Soc. 123, 9015-9020 (2001). 